\title{
Game-Theory Approach on a University-Industry Collaboration Model
}

\section{Dr. Jing Zhang, Virginia State University}

Assistant professor, Department of Mathematics and Economics, Virginia State University

Yongjin Lu, Virginia State University

Dr. Zhifu Xie, Virginia State University

Professor, Department of Mathematics and Economics Virginia State University

Ph.D in Mathematics, Brigham Young University, Aug. 2006

Dr. Dawit Haile, Virginia State University

Dr. Keith Williamson, Virginia State University

Dr. Keith M Williamson is the Dean of the College of Engineering and Technology and a Professor of both Manufacturing Engineering and Mechanical Engineering Technology. Before starting his career in academia, Williamson served as a naval architect and electronics engineer for the Department of the Navy and received the Civilian Service Medal for his efforts during the first Gulf War.

Dr. Williamson's teaching, research, and publication interests span a range of topics including transport phenomena, metallurgy, thermomechanical stir processing, and university-K12 partnerships. He is a strong advocate for information technology literacy within public schools, He is the past Secretary and current member of the Board of Directors for the Commonwealth Center for Advanced Manufacturing (CCAM) which is a public-private partnership between Virginia's top research universities and advanced manufacturers including Airbus, Rolls-Royce, Siemens, and Newport News Shipbuilding. Williamson also serves as the Chair of the Board of Directors for the Commonwealth Center for Advanced Logistics Systems (CCALS) and as Founding Secretary of the Board of Directors for the Virginia State University Research Foundation.

Williamson holds a Ph.D. in mechanical engineering from Tufts University, a M.S. in mechanical engineering from Northeastern University, and a B.S. in mechanical engineering from Bucknell University. 


\title{
GAME THEORY APPROACH ON A UNIVERSITY-INDUSTRY COLLABORATION MODEL
}

\author{
JING ZHANG, YONGJIN LU, ZHIFU XIE \\ DEPARTMENT OF MATHEMATICS AND ECONOMICS \\ E-MAIL: JIZHANG@VSU.EDU,YLU@VSU.EDU, ZXIE@VSU.EDU \\ DAWIT HAILE, KEITH WILLIAMSON \\ DEPARTMENT OF ENGINEERING AND COMPUTER SCIENCE \\ E-MAIL: DHAILE@VSU.EDU, KWILLIAMSON@VSU.EDU \\ VIRGINIA STATE UNIVERSITY \\ PETERSBURG, VA 23806
}

\begin{abstract}
In the fiercely competitive global marketplace, innovation alone is no longer enough. University-industry collaboration has been identified to be one of game changer to sustain the innovation ecosystem. Many research centers have been established to provide a platform for collaboration between university researchers and industrial research managers. Its benefits are substantial to both ends. The benefits are mutual, particularly in terms of students who complete university programs and join industry research and development teams. The U-I collaboration, on one hand, brings in ideas in the academic forefront to accelerate technological advancement in industrial firms, on the other hand, strengthens the education of engineers and mathematicians, and economists at universities by providing research projects generated by real technological issues from industry. It is clear that this marriage invigorates the current stereotype engineering education through new industrial challenges. However, not many university-industrial ties are as well established as university to university or company to company collaborations within academia or within industry. Thus, it is imperative to conduct a scientific study on the mechanism of university-industry collaborations and provide insights on possible measures and strategies that research centers can take to promote university-industry links. In this paper, we establish a mathematical model for the utility of both collaborative parties in a university-industry collaboration network. We analyze the criteria a firm should apply to select an academic collaborator to optimize its utility from its R\&D investment which includes an investment in a future workforce. We also analyze the criteria a university engineering research team should apply to select a project from a firm to enhance its research capacity and diversify its engineering programs as well.
\end{abstract}

Keywords: Stock of Knowledge, Cooperative Game, Noncooperative Game, Economic Network, Optimization.

Date: May, 2016. 


\section{INTRODUCTION}

In the current global knowledge-and-technology intensive marketplace, the $R e$ search and Development (R\&D) department plays a vital role in the development of a firm or an industry. During the last decade, we have seen a rapid increase in the research of $R \& D$ collaboration in econometric scale, much of which is among firms or inside industry. However in the fiercely competitive global marketplace, innovation alone is no longer enough. A rising trend of university-industry collaboration provides a more open platform for innovation and is given increasing attention from local and federal government. It is a game changer in that it reduces time-tomarket for new findings and new ideas in the academic forefront into economic value.

In U.S., more and more organizations have been established to provide a platform for collaboration between firms and research institutions. In the report of the President's Strategy, "A Strategy for American Innovation", some policies have been identified to sustain the innovation ecosystem that will deliver benefits to all Americans [1]. The Administration has consistently called for sustaining America's long-term economic competitiveness and growth through robust investments in the building blocks of the American innovation ecosystem. For example, the National Network for Manufacturing Innovation (NNMI) aims to create a competitive, effective, and sustainable manufacturing research-to-manufacturing infrastructure. Usually, the new fundamental results from federally funded research such as National Science Foundation have a very slow and uncertain path to commercial viability. The Administration's Lab-to-Market Initiative is working to accelerate technology transfer for promising new innovation. The Federal Government is also playing a critical role in supporting regional efforts to strengthen local and regional innovation ecosystems that sustain economic growth and job creation.

Many states have established different centers which provide a platform for collaboration. In some of the centers, universities lead a consortium to identify new and emerging areas that would benefit from shared public-private investment in research and development, education and training. On the other hand, in some other centers, companies lead a consortium to identify new and emerging areas of the industry that would turn ideas into payoff faster and more affordably than ever before. Such cooperative economic networks among companies, universities, and local governments (CUG) have been studied in terms of their stability and efficiency [7].

From a university's perspective, its tie to the industry goes beyond grants. University engineering, mathematics, and economics programs have been widely criticized for lack of practical training. Its goal focuses more on students' understanding of empirical conclusions in each discipline, but less on students' skills of creatively applying their knowledge for solutions of real world engineering problems. However, these skills are what industrial firms really hope to find from their prospective employees. This is referred as gap between graduates' readiness and industry's requirement and has been studied in the areas such as software engineering [11. Overall, science, technology, engineering, and mathematics (STEM) education has 
firm roots in the industrial development. To bridge the aforementioned gap, the most direct approach is to bring in real industrial projects and incorporate them in the engineering programs. From this angle, U-I collaborations provide excellent opportunities for engineering students to gain hands-on experience that will potentially benefit their future industrial career, and U-I collaborations have substantial impact on boosting the quality of university engineering education by introducing practical training to traditional pedagogy of engineering education.

From a firm's perspective, a significant advantage of university-industry collaboration is that it overcomes the issues of knowledge sharing and knowledge management it needs to face when collaborating with its competitors. When a firm decides to work with a research team in a university for innovations, the next question for them would be how to find an academic collaborator? Data has shown that such university-industry link is usually local, for a lower cost of the interactions between the collaborative parties [10. At this local network level, it is still critical for a firm to select its academic collaborator to maximize the outcome of their investment. In this study, we establish a mathematical model of utility (or payoffs) of both collaborative parties in a university-industry link. Then we analyze the criteria a firm should apply to select an academic collaborator to optimize its payoff from its R\&D investment. We also analyze the criteria a research team should apply to select a research project from a firm to advance its stock of knowledge.

In our model, a firm links to a university to form a R\&D research consortium to conduct an innovation $\mathrm{R} \& \mathrm{D}$ project. The firm provides the investment, which is the cost of project conduction carried out at the university. The university receives the investment and conduct the research for the project. The outcome of these projects, in the form of stock of knowledge and preparation for students, benefits both sides and gives a win-win situation: the firm uses the new innovation to reduce its production cost; the university, in addition of obtaining investment, increases its research capacity, which in turn enhances its ability to produce well prepared graduates and potential for additional grants as well as its reputation among universities.

Past theoretical research on cooperative research and development (CRD) among profit oriented firms are abundant in the literature and has focused on various aspects of the cooperation. Some of the research presented in the managerial literature $[12,13,14,15,16,17,18,19]$ claim that the main motivation of CRD among companies is scale-based which implicitly implies that R\&D generates only new information and the principal purpose of CRD therefore is to share costs. A typical assumption in this approach is that all firms are symmetrical in terms of their capabilities or knowledge. This assumption unfortunately limits the possible application of this approach. In contrast, an alternative approach suggests that the CRD not only generates new information but also enhances the firm's ability to assimilate and exploit existing information, therefore, $R \& D$ could be viewed as a learning process and cooperative R\&D could be modeled based on "the stock of knowledge" of firms 
in alliances. This approach also has relaxed assumption that allows firms in consortium to have heterogeneous capabilities. Literature on this robust way of modeling CRD could date back to the late 1980s [20, 21, 22] and has since been applied to explain various organizational phenomena, such as the large-scale reliance on interorganizational collaborations in the biotechnology industry [23], the role of direct ties, indirect ties and structural holes in a firm's network of relations on innovation [24] and the relationship between the openness of firms' external search strategies and their innovative performance [25], just to name a few. Readers could also consult [26] for a more comprehensive review.

Introduced in 1940s by von Neumann and Morgenstern [27], modern game theory as the study of "mathematical models of conflict and cooperation between intelligent rational decision-makers" [28] is poised ideally to analyze the resource-based models of CRD reviewed above. As a matter of fact, various tools and concepts in game theory have already been utilized to analyze these models in a number of applications. For example, prisoner's dilemma is used in [29] to analyze alliance behavior towards an opportunistic partner; in 30 to argue that reputation might benefit collaboration in two-firm collaboration; evolutionary game theory is used in [31] to determine whether or not to collaborate and the amount of collaboration in e-collaboration game with discrete strategies; non-cooperative non-zero sum games are used in [32 to model and analyze equilibrium in a coopetition (collaboration to compete) situation; fuzzy sets theory is used in [33] to model team behavior of multifunctional product design teams towards design alternatives.

Among all these applications, one that is most closely related to our article is [9] where the model suggests that if consortium participants possess complementary knowledge, the participation increases the degree of knowledge sharing, intensifies firms' R\&D efforts to learn from other members and more importantly, enhances social welfare which may be viewed form either the workforce aspect or in terms of the general advance of knowledge, justifying government's support for these projects. Major departure of our model is that different from the previously reviewed literature where collaboration in a network of commercial companies is studied, in this article, we study the collaboration in a two-party network of commercial firms and research teams in universities. Research teams in universities play an important role in the collaboration: the actual personnel who solve the research problems are faculty member and mathematics or engineering students who are part of the research teams, not the research scientists employed by commercial firms. A direct implication of this is that the utility of research teams under this U-I framework should not be measured by monetary value, rather, it should be measured by the educational benefits in the form of increase in research capabilities of (faculty and student) members of the research teams. This is the reason why we chose to work with the concept of stock of knowledge. Another more subtle implication is that in contrast to [9], where the degree of knowledge sharing, or knowledge spillover, is a very important factor to consider due to the competition between firms, our model assumes that mutual trust between the two ends is solid, and the knowledge 
produced during the collaboration will be completely delivered to both sides without reservation. Our goal here is to analyze and identify the factors and conditions that could contribute to a greater utility of both parties in the network. This would provide certain guideline to help sustain the collaboration in this kind of network where commercial firms benefit from a saving of $R \& D$ costs while both universities and companies benefit from producing more job-ready students. In what follows, the word "value" will be used in a very liberal sense. It is referred to not just the traditional monetary return when associated with utility of university research teams, but also the increase in reserve of knowledge.

The organization of the paper is as follows. In section 2, we build the mathematical model for the collaboration between a firm and a research team in a university. The fundamental assumptions for the model are also discussed. In section 3 , by applying some simple but appropriate formulations which fulfill the assumptions of the model, we are able to conduct game theoretical analysis and some very interesting results are proved. At the last section, the results of our model and analysis are summarized and some conclusions are made.

\section{Notation and Mathematical Model}

This section introduces the notations and the mathematical model of the payoff for both the firm and the university, as well as the assumptions underlying the mathematical model.

\subsection{Decision Variables.}

$z \quad$ The stock of knowledge which is also mapped to the number journals, patents and students thesis produced or affiliated with the research

$M$ The investment from the firm

$N$ The research capacity of the university

$\gamma$ The relevance of the university research team to the firm's innovation project

$\beta$ The intensity that the university research team will engage to the firm's innovation project

Remark 1. $N$ the research capacity includes the labor force of research staff including students and all the equipments, facilities a university possesses for research purpose. $\gamma$ measures the matchness between the firm's innovation project and university research team's capacity, it is a number between 0 and 1. $\beta$ measures the percentage of research capacity that a university research team will devote to the firm's innovation project. It is also a number between 0 and 1 .

2.2. Assumptions. To develop the model, we make the following assumptions:

(1) The network includes enough number of firms and universities, such that both sides have the chance to select their collaborator for research conduction, which means not only a firm can choose a university to collaborate with, but vice versa. For the sake of simplification, we assume that one firm can only link to one university at one time, and one university can only link to one firm at one time as well. 
(2) The collaboration creates added value to the firm's product development process by reducing the production cost ([3, [4]), and to the university by increasing the university's research capacity $N$ for advanced knowledgement.

(3) The collaboration engenders coordination cost, and when the stock of knowledge is applied to product development, integration cost is incurred ([3], [4]). Both the coordination and integration cost are not included in the investment $M$. Let us name the sum of coordination cost and integration cost as collaboration cost. The collaboration cost depends on the relevance of the university to the innovation project $\gamma$ and the intensity of the project conduction $\beta$ as well.

(4) University research capacity $N$ depends on the university size and reputation. Larger universities typically have more faculty with stronger reputations and because of size typically more capacity. As such, the outcome of the collaboration $z$ has a tendency to be larger than smaller universities. However, the marginal cost of project conduction (such as the usage of the research facilities, the payment to the research staff) at larger university will be higher.

2.3. Formulation of the Stock of Knowledge. The stock of knowledge $z$, the outcome of the collaboration, is the added value created by the collaboration. It is determined by $M, N, \gamma$ and $\beta$. Inspired by [5] and [8], we propose $z$ satisfies the Cobb-Douglas production function:

$$
z=k(\gamma) M^{\alpha} N^{\lambda_{1} \beta+\lambda_{2}}
$$

In (1), the output elasticity for capital $\alpha$ is between 0 and 1 . We assume the output elasticity for labor is linear to $\beta$, the university's intensity of the project engagement, thus is denoted by $\lambda_{1} \beta+\lambda_{2}$ and satisfies $0<\lambda_{1} \beta+\lambda_{2}<1$. The productivity factor $k(\gamma)$ satisfies the first derivative $k_{\gamma}>0$ and second derivative $k_{\gamma \gamma}<0$, which indicates the stock of knowledge will increase as the firm chooses a university that has more relevance with their innovation project, but the rate of such increase decays as relevance increases.

2.4. Formulation of the Firm's Model. Here we adapt the model in [4] and [3]. The payoff of the firm from the collaboration satisfies:

$$
\begin{aligned}
\text { firm's payoff }= & \text { added value of collaboration to the firm }- \text { project investment } \\
& - \text { collaboration cost }- \text { production cost }
\end{aligned}
$$

We assume the "added value of collaboration to the firm" is proportional to $z$, the stock of knowledge created in the collaboration. The production cost also depends on $z$. Production cost reduces if stock of knowledge increases. Thus we denote production cost as $c^{i}(z)$, where the first derivative $c_{z}^{i}<0$. In addition, let $s(\beta, \gamma)$ denote the collaboration cost. The mathematical model for the firm's payoff is:

$$
\Pi^{I}=b_{1} z-M-s(\beta, \gamma)-c^{i}(z)
$$

where $b_{1}$ is a positive constant and $b_{1}>>0$. We assume furthermore that $s(\beta, \gamma)$ is convex with respect to both $\beta$ and $\gamma$. The collaboration cost increases as the 
relevance $\gamma$ decreases, but at a decay rate. That is, $s_{\gamma}<0$ and $s_{\gamma \gamma}>0$. And $c^{i}(z)$ is also convex with respect to $z$.

2.5. Formulation of the University's Model. The payoff of the university from the collaboration satisfies:

$$
\begin{aligned}
\text { university's payoff }= & \text { added value of collaboration to the university } \\
& + \text { project investment }- \text { project conduction cost }
\end{aligned}
$$

We assume the "added value of collaboration to the university" is proportional to $z$. And it is also proportional to the degree of knowledge complementarity, which is the degree of irrelevance, i.e. $1-\gamma$. Project conduction cost depends on university research capacity $N$, the intensity of the university's engagement to the project conduction $\beta$, and the relevance of university research team to the innovation project $\gamma$. Thus the mathematical model is

$$
\Pi^{U}=b_{2}(1-\gamma) z+M-c^{u}(N, \beta, \gamma)
$$

where $b_{2}$ is a positive constant. We further assume that the less relevance $\gamma$ can lead to an increase in the university's project conduction cost, but at a decay rate. This indicates $c_{\gamma}^{u}<0$ and $c_{\gamma \gamma}^{u}>0$

\section{Game Theoretical Analysis}

For the purpose of simplicity, the stock of knowledge $z$, the collaboration cost $s(\beta, \gamma)$, the firm's production cost $c^{i}(z)$, and the university's project conduction $\operatorname{cost} c^{u}(N, \beta, \gamma)$ are given by the simple formulations that bear all the assumptions in section 2 .

3.1. Formulations of the Models. Based on the assumption of section 2, we define $z, s(\beta, \gamma), c^{i}(z)$ and $c^{u}(N, \beta, \gamma)$ as follows:

$$
\begin{aligned}
& z(M, N, \beta, \gamma)=K \frac{\gamma}{1+\gamma} M^{\alpha} N^{\lambda_{1} \beta+\lambda_{2}} \\
& s(\beta, \gamma)=I \beta^{2}(1-\gamma)^{2} \\
& c^{i}(z)=\tau_{1}-\tau_{2} z \\
& c^{u}(N, \beta, \gamma)=\frac{r N \beta}{1+\gamma}
\end{aligned}
$$

where $K, I, \tau_{1}, \tau_{2}$ and $r$ are all positive constant.

With the above expressions, the payoff $\Pi^{I}$ and $\Pi^{U}$ becomes

$$
\begin{gathered}
\Pi^{I}=b_{1} z-M-I \beta^{2}(1-\gamma)^{2}-\left(\tau_{1}-\tau_{2} z\right) \\
\Pi^{U}=b_{2} z+M-\frac{r N \beta}{1+\gamma}
\end{gathered}
$$

3.2. Non-Cooperative Game. In this part, we look into the noncooperative game between the firm and the university in this collaboration. In a noncooperative game, each party optimizes its own payoff based on available information and data. 
3.2.1. The Firm's Game. On the firm's side, with a investment budget $M$. The selection of an innovation collaborator (from the pool of universities) is crucial to their payoff. The available variables for a firm to make such decision is (1) a university's size and reputation, or in the current scenario, a university's research capacity $N$. (2) a university's relevance to the firm's innovation project $\gamma$. Our study leads to the following results:

Claim 1. The increase of university research capacity $N$ will increase the firm's payoff $\Pi^{I}$ from the $U-I$ collaboration, at a rate that decays.

Proof. Consider the first order of the firm's payoff $\Pi^{I}$ with respect to the research capacity $N$ :

$$
\frac{\partial \Pi^{I}}{\partial N}=b_{1} z_{N}-\frac{\partial c^{i}}{\partial z} z_{N}=\left(b_{1}+\tau_{2}\right) \frac{\lambda_{1} \beta+\lambda_{2}}{N} z>0
$$

The second order condition of $\Pi^{I}$ with respect to $N$

$$
\frac{\partial^{2} \Pi^{I}}{\partial N^{2}}=\left(b_{1}+\tau_{2}\right) \cdot\left(-\frac{\lambda_{1} \beta+\lambda_{2}}{N^{2}} z+\frac{\left(\lambda_{1} \beta+\lambda_{2}\right)^{2}}{N^{2}} z\right)<0
$$

Remark 2. Claim 1 shows that when all other factors fixed, a firm will choose to collaborate with the university that has the largest research capacity, or the best reputation. But when the research capacity reaches certain level ( $N$ large enough), the impact of different research capacity between universities becomes less relevant to the firm's payoff, other factors may play a more important role for the optimization of the firm's payoff over the U-I collaboration.

Claim 2. The increase of $\gamma$, the relevance of university research team to the innovation project will increase the firm's payoff $\Pi^{I}$ from the $U$-I collaboration, at a rate that decays.

Proof. Consider the first order of firm's payoff $\Pi^{I}$ with respect to the relevance $\gamma$ :

$$
\begin{aligned}
\frac{\partial \Pi^{I}}{\partial \gamma} & =b_{1} z_{\gamma}+2(1-\gamma) I \beta^{2}-\frac{\partial c^{i}}{\partial z} z_{\gamma} \\
& =\left(b_{1}+\tau_{2}\right) \frac{1}{\gamma(1+\gamma)} z+2(1-\gamma) I \beta^{2}>0
\end{aligned}
$$

The second order of $\Pi^{I}$ with respect to $\gamma$ :

$$
\begin{aligned}
\frac{\partial^{2} \Pi^{I}}{\partial \gamma^{2}} & =\left(b_{1}+\tau_{2}\right)\left[\left(-\frac{1}{\gamma^{2}}+\frac{1}{(1+\gamma)^{2}}\right) z+\frac{1}{\gamma(1+\gamma)} z_{\gamma}\right]-2 I \beta^{2} \\
& =-\frac{2\left(b_{1}+\tau_{2}\right)}{\gamma(1+\gamma)^{2}} z-2 I \beta^{2}<0
\end{aligned}
$$

Remark 3. Claim 2 and its proof shows that when all other factors fixed, a firm will choose to collaborate with the university that is most relevant to its innovation project. However, when the relevance $\gamma$ is large enough, other factors may 
play a more important role for the optimization of the firm's payoff over the U-I collaboration.

Compare (6) and (8), the first order of $\Pi^{I}$ respect to $N$ and $\gamma$. Keep in mind $0<\gamma<1,0<\lambda_{1} \beta+\lambda_{2}<1, N>>1$ and $I>>1$, We arrive at

$$
\frac{\partial \Pi^{I}}{\partial N}=\left(b_{1}+\tau_{2}\right) \frac{\lambda_{1} \beta+\lambda_{2}}{N} z<\left(b_{1}+\tau_{2}\right) \frac{1}{\gamma(1+\gamma)} z+2(1-\gamma) I \beta^{2}=\frac{\partial \Pi^{I}}{\partial \gamma}
$$

(10) infers the following important result:

Claim 3. The relevance of a university's research team to the firm's innovation project $\gamma$ has a larger marginal effect than its research capacity $N$ to the payoff of the firm.

Remark 4. Claim 3 indicates when a firm makes the decision as to which university they should collaborate with for their innovation project, relevance of a university to the project should be put into priority over its research capacity (or its reputation).

3.2.2. The University's Game. A university, in order to maximize its payoff, need to link to the correct firm (or innovation project) that allows the university to exploit its research capacity and support for students the most. The available variables for a university to plan the utilization of its research capacity are: (1) A firm's investment for its innovation project $M$; (2) The intensity of university's engagement to the innovation project $\beta$.

Claim 4. The increase of the investment $M$ in an innovation project increases the university's payoff $\Pi^{U}$ from the U-I collaboration.

Proof. Consider the first order of university's payoff $\Pi^{U}$ with respect to the investment $M$ :

$$
\frac{\partial \Pi^{U}}{\partial M}=b_{2}(1-\gamma) z_{M}+1=\frac{\gamma-\gamma^{2}}{1+\gamma} b_{2} K \alpha M^{\alpha-1} N^{\lambda_{1} \beta+\lambda_{2}}+1>0
$$

Furthermore,

$$
\frac{\partial}{\partial \gamma}\left(\frac{\partial \Pi^{U}}{\partial M}\right)=\frac{1-2 \gamma-\gamma^{2}}{(1+\gamma)^{2}} b_{2} K \alpha M^{\alpha-1} N^{\lambda_{1} \beta+\lambda_{2}}
$$

Let $\gamma_{0}=-1+\sqrt{2}$. It can be seen that $0<\gamma_{0}<1$ and $\gamma_{0}$ is the zero of $\frac{\partial}{\partial \gamma}\left(\frac{\partial \Pi^{U}}{\partial M}\right)$. For $\gamma>\gamma_{0}, \frac{\partial}{\partial \gamma}\left(\frac{\partial \Pi^{U}}{\partial M}\right)<0$. This indicate that the marginal payoff with respect to investment $M$ decreases as $\gamma$ increases when $\gamma>\gamma_{0}$. This result lead to the following important claim:

Claim 5. When two innovation projects provide same investments $M$ and when university's relevance to both projects reaches a level of more than $\gamma_{0}$, a university will choose to collaborate with the project where it has less relevance in order to maximize its payoff. 
Remark 5. The logics behind Claim 5 is that participating in the project where it is hopes to grow expertise will provide more benefit to its students in the long term and to faculty in the near term. Providing the means to advance its reputation among firms increasses complementarity, and augments the research capacity, and ultimately a higher payoff. In some cases, companies has decided to increase its level of engagement with smaller universities to leverage specific expertise and attract a broader pool of students and capabilities.

Next, we discuss the impact of $\beta$, intensity of a university's engagement in an innovation project to its own payoff $\Pi^{U}$.

Consider the first order of $\Pi^{U}$ with respect to $\beta$,

$$
\begin{aligned}
\frac{\partial \Pi^{U}}{\partial \beta} & =b_{2}(1-\gamma) z_{\beta}-\frac{r N}{1+\gamma} \\
& =b_{2}(1-\gamma) \frac{K \gamma}{1+\gamma} M^{\alpha} N^{\lambda_{1} \beta+\lambda_{2}} \cdot \lambda_{1} \ln N-\frac{r N}{1+\gamma}
\end{aligned}
$$

From (13), we solve for the critical point of the first order,

$$
\beta^{*}=\frac{1}{\lambda_{1}}\left[\frac{\ln \left(\frac{r N}{\lambda_{1} b_{2} K\left(\gamma-\gamma^{2}\right) M^{\alpha} \ln N}\right)}{\ln N}-\lambda_{2}\right]
$$

Claim 6. To optimize its own payoff from the collaboration, the intensity a university engages in an innovation project should be $\beta^{*}$ given in (14).

Consider the first order of $\beta^{*}$ with respect to $\gamma$

$$
\begin{aligned}
\frac{\partial \beta^{*}}{\partial \gamma} & =\frac{1}{\lambda_{1} \ln N}\left(-\frac{1}{1-\gamma}+\frac{1}{\gamma}\right) \\
& =\frac{1}{\lambda_{1} \ln N}\left(\frac{1-2 \gamma}{\gamma-\gamma^{2}}\right)
\end{aligned}
$$

This result gives to the following claim:

Claim 7. For $0<\gamma<1 / 2$, a university's optimal engagement to an innovation project $\beta^{*}$ decreases as $\gamma$ increases. For $1 / 2<\gamma<1, \beta^{*}$ increases as $\gamma$ increases.

Remark 6. Claim 7 shows, when a university's relevance to an innovation project is low, the project costs require a large expenditure of resource (including both labor and equipment). But such expenditure decreases when relevance increases. On the contrary, when a university's relevance to an innovation project is high, the university's expenditure on the innovation project is less. However, to achieve its optimal payoff, the university's resource expenditure has to increase and align with relevance to increase payoff in terms of reputation and quality of results. In some cases, if expenditures for larger universities decrease with increasing relevance, there is a possibility of reputational risk. In such cases, the university fails to meet industry expectations. 
The analysis of Remark 6 echoes Remark 5 that, driven by its long run payoff, a university prefers to collaborate with the innovation project that it has less expertise in.

3.3. Cooperative Game. In a cooperative game, the alliance of a firm and a university aims at maximize their combined payoff $\Pi^{C}$. Following [2] and [6], $\Pi^{C}$ satisfies

$$
\Pi^{C}=\phi \Pi^{I}+(1-\phi) \Pi^{U}, \quad 0<\phi<1 .
$$

Plug in (4) and (5) to (17),

$$
\Pi^{C}=\phi\left[b_{1} z-M-I \beta^{2}(1-\gamma)^{2}-\left(\tau_{1}-\tau_{2} z\right)\right]+(1-\phi)\left[b_{2}(1-\gamma) z+M-\frac{r N \beta}{1+\gamma}\right]
$$

The following analysis is based on the scenario that the link between a firm and a university has formed and an innovation project is going to start.

Consider the first order of $(18)$ with respect to $M$,

$$
\frac{\partial \Pi^{C}}{\partial M}=\left[\phi b_{1}+\phi \tau_{2}+b_{2}(1-\phi)(1-\gamma)\right] z_{M}-2 \phi+1
$$

where

$$
z_{M}=\alpha K \frac{\gamma}{1+\gamma} M^{\alpha-1} N^{\lambda_{1} \beta+\lambda_{2}}=\alpha \frac{z}{M}
$$

Combine 19 and 20 , and solve $\frac{\partial \Pi^{C}}{\partial M}=0$ for $\phi$, we get

$$
\phi^{*}=\frac{M+b_{2}(1-\gamma) \alpha z}{2 M-\alpha z\left(b_{1}+\tau_{2}-b_{2}+b_{2} \gamma\right)}
$$

Claim 8. Given the investment $M$, the proportion $\phi$ associated to $M$ that will maximize the combined payoff $\Pi^{C}$ of the research alliance is given in 21.).

Consider that $0<\phi^{*}<1$, (21) has to satisfy

$$
2 M-\alpha z\left(b_{1}+\tau_{2}-b_{2}+b_{2} \gamma\right)>0
$$

and

$$
M+b_{2}(1-\gamma) \alpha z<2 M-\alpha z\left(b_{1}+\tau_{2}-b_{2}+b_{2} \gamma\right)
$$

The constraints in $(22)$ and $(23)$ together yields,

$$
\frac{\gamma}{1+\gamma} N^{\lambda_{1} \beta+\lambda_{2}}<\frac{M^{1-\alpha}}{K \alpha\left(b_{1}+\tau_{2}\right)}
$$

(24) shows, for a given investment $M$, the university related variables $(N, \beta, \gamma)$ should satisfy certain condition (24) to enter a cooperative relationship with a firm to achieve their optimal combined payoff $\Pi^{C}$.

Remark 7. With large $N$, 24 will not be able to hold. This leads to $\phi^{*}>1$ and $1-\phi^{*}<0$, which means the combined payoff of the research alliance $\Pi^{C}$ is maximized at the sacrifice of the payoff of the university part. This gives the anther reason of the top-rated university's reluctance of collaboration with less invested innovation project. 


\section{Conclusion and Future Work}

In this study, we establish a university-industry collaboration model. We formulate the production of knowledge using Cobb-Douglas function. Based on this, we develop the mathematical models of the payoff for both the firm and the university. We further give a detailed analysis on the selection of collaborator on innovation project from the perspectives of both sides, in both non cooperative game and cooperative game settings. Under that assumption that (1) at one time a firm can only link to one university and a university can only link to one firm, (2) a firm or a university will not enter a collaboration relation if there is limited payoffs to themselves, the following results are obtained:

(1) In general a firm will choose to collaborate with larger universities with better reputations and more relevance to their innovation project.

(2) A university's relevance to a firm's innovation project has a more important marginal effect to the firm's payoff over the university's reputation (rank). Thus, when a firm's makes the decision on which university to collaborate, they may place a higher priority on relevance over reputation (rank).

(3) A university prefers to collaborate with on an innovation project that is most aligned with its capability and support for students.

(4) When two projects have the similar investment package and both of their relevance to a university's capacity reaches certain level, the university may choose to collaborate with the project that is less aligned with its capabilities in order to gain expertise in an area that is more complementary and enhance its research capacity in the long run.

(5) A university's relevance to an innovation project impacts a university's cost (of both labor and equipment) in conducting this project. When two projects are not equally aligned to a university's capabilities, but each exceeds a critical alignment level, the the university may choose to collaborate on the project that is less aligned in order to to achieve its maximum payoff in terms of additional capability and advanced reputation.

(6) For a firm and a university to enter a cooperative collaboration with agreement on proportions each part contributes to their combined payoff, the firm's investment and the university's research capacity need to well aligned. A large university with large expenses for research capacity may be reluctant to collaborate to small funded innovation with low payoff and high risk to its current reputation. Smaller universities with aligned capabilities may be better suited for low payoff projects with reputational payoffs above the value of its current reputation.

Our future work will extend the current one-to-one collaboration model to one-tomany version, i.e. one firm collaborates with more than one universities for one innovation project. Furthermore, we hope to explore the many-to-many universityindustry collaboration, that is, several firms co-invest on an innovation project which will be conducted by the collaboration of several universities. To these ends, numerical studies will complement analytical studies when solutions no longer possess a closed form. 


\section{REFERENCES}

[1] A Strategy for American Innovation, National Economic Council and Office of Science and Technology Policy, October 2015.

[2] P. L. Abad and C. K. Jaggi, Joint Approach for Setting Unit Price and the Length of the Credit Period for a Seller when End Demand is Price Sensitive, International Journal of Production Economics, 83 (2003), 115-122.

[3] J. Arsenyan, G. Buyukozkan and O. Feyzioglu, Modelling Collaboration Formulation with a Game Theory Approach, Proceedings of the World Congress on Engineering 2011, vol. 1, (2011), 763-767.

[4] S. R. Bhaskaran and V. Krishnan, Effort, Revenue and Cost Sharing Mechanisms for Collaborative New Product Development, Management Science, 55(6) (2009), 1152-1169.

[5] L. Branstetter and M. Sakakibara, Japanese Research Consortia: A Microeconometric Analysis of Idustrial Policy, Journal of Industrial Economics, 46(2) (1998), 207-233.

[6] M. Esmaeili, M. Araynezhad and P. Zeephongsekul, A Game Theory Approach in Seller-Buyer Supply Chain, European Journal of Operation Research, 195 (2009), 442-448.

[7] Y. Lu, Z. Xie and J. Zhang, An Analysis of the Stability and Efficiency of a Cooperative Network among Companies, Universities and Local Government, Journal of Game Theory, 2(3) (2013), 23-32.

[8] K. Motohashi, Economic Analysis of University-Industry Collaboration: The Role of New Technology Based Firms in Japanese National Innovation Reform, The Research Institution of Economy, Trade and Industry, Discussion Paper Series 04-E-001, (2004).

[9] M. Sakakibara, Knowledge Sharing in Cooperative Research and Development, Manage. Decis. Econ., 24 (2003), 117-132.

[10] R. Veugelers and B. Cassiman, REBD Cooperation between Firms and Universities: Some Empirical Evidence from Belgian Manufacturing, International Journal of Idustrial Organization, 23(5) (2005), 355-379.

[11] N. E. A. M. Almi, N. A. Rahman, D. Purusothaman, and S. Sulaiman Software engineering education: The gap between industry's requirements and graduates' readiness, 2011 IEEE Symposium on Computers \& Informatics (ISCI), (2011), 542-547.

[12] M. L. Katz, An analysis of cooperative research and development, RAND Journal of Economics, 17 (1986), 527-543.

[13] C. d'Aspremont and A. Jacquemin Cooperative and noncooperative R\&D in duopoly with spillovers, American Economic Review, 78 (1988), 1133-1137.

[14] J. P. Choi Essays in the Theory of Dynamic R\&D Competition, Ph.D. Thesis, Harvard University.

[15] M. L. Katz and J. A. Ordover RED cooperation and competition, Brookings Papers on Economic Activity: Microeconomics, (1990), 137-203.

[16] M. Motta Cooperative RESD and vertical product differentiation, International Journal of Industrial Organization, 10 (1992), 643-661.

[17] K. Suzumura Cooperative and noncooperative R\&D in an oligopoly with spillovers, American Economic Review, 82 (1992), 1307-1320.

[18] S. Ziss Strategic RED with spillovers, collusion and welfare, Journal of Industrial Economics, 42 (1994), 375-393.

[19] S. W. Salant and G. Shaffer Optimal asymmetric strategies in research joint ventures, International Journal of Industrial Organization, 16 (1998), 195-208.

[20] W. M. Cohen and D. A. Levinthal Innovation and learning: the two faces of R\&D, Economic Journal, 99 (1989), 569-610.

[21] R. C. Levin, A. K. Klevorick, R. R. Nelson and S. G. Winter Appropriating the returns from industrial research and development, Brookings Papers on Economic Activity, 3 (1987), 783-820.

[22] F. Kodoma Direct and indirect channels for transforming scientific knowledge into technical innovations, Transforming Scientific Ideas into Innovations: Science Policy in the United States and Japan, Bartocha B, Okamura S (eds). Japan Society for the Promotion of Science: Tokyo, Japan. 
[23] W. W. Powell, K. W. Koput and L. Smith-Doerr Interorganizational collaboration and the locus of innovation: Networks of learning in biotechnology, Administrative science quarterly, (1996), 116-145.

[24] G. Ahuja Collaboration networks, structural holes, and innovation: A longitudinal study, Administrative science quarterly, 45(3) (2000), 425-455.

[25] K. Laursen and A. Salter Open for innovation: the role of openness in explaining innovation performance among UK manufacturing firms, Strategic management journal, 27(2) (2006), 131-150.

[26] S. A. Zahra and G. George Absorptive capacity: A review, reconceptualization, and extension, Academy of management review, 27(2) (2002), 185-203.

[27] J. von Neumann and O. Morgenstern Theory of Games and Economic Behavior, New Jersey: Princeton University Press, 1944.

[28] R. B. Myerson Game Theory: Analysis of Conflict, Harvard University Press, 1990.

[29] S.E. Phelan, R.J. Arend, and D.A. Seale Using an Iterated Prisoner's Dilemma with Exit Option to Study Alliance Behavior: Results of a Tournament and Simulation, Computational \& Mathematical Organization Theory, 11(4) (2005), 339-356.

[30] R.J. Arend Reputation for cooperation: contingent benefits in alliance activity, Strategic Management Journal, 30 (2009), 371-385.

[31] G. Cai and N. Kock An evolutionary game theoretic perspective on e-collaboration: The collaboration effort and media relativeness, European Journal of Operational Research, 194(3) (2009), 821-833.

[32] W. Amaldoss, R.J. Meyer, J.S. Raju, and A. Rapoport Collaborating to Compete, Marketing Science, 19(2) (2000), 105-126.

[33] L. Chen and S. Li Modeling Concurrent Product Design: A Multifunctional Team Approach, Concurrent Engineering, 8(3) (2000), 183-198. 